\title{
An Application of the Multiple Knapsack Problem: The Self-Sufficient Marine
}

\author{
Jay Simon ${ }^{1}$, \\ jaysimon@american.edu \\ Aruna Apte ${ }^{2}$, \\ auapte@nps.edu \\ Eva Regnier ${ }^{2}$, \\ eregnier@nps.edu \\ ${ }^{1}$ Kogod School of Business \\ American University \\ ${ }^{2}$ Graduate School of Business and Public Policy \\ Naval Postgraduate School
}

$6 / 22 / 2016$

\begin{abstract}
Self-Sufficiency (SS) is the ability to maintain capability without external support or aid. Operations in austere environments with limited functional infrastructure and logistical support, which are common in humanitarian assistance and disaster relief as well as military operations, must be self-sufficient. In this paper, we explore the challenges of SS in the United States Marine Corps (USMC). Marines engage in a wide variety of expeditionary operations, and must function without logistical support for long stretches of time. They face competing constraints, including the load that a squad can carry, mission requirements, resources required for sustainment, and the extent to which resources can be shared. We extend the knapsack problem in several ways to model a Marine squad's decisions regarding what items to carry and how to distribute them. The Office of Naval Research found the models and the results to be significant as baseline analysis for the resource demands of a self-sufficient squad. Though the data and scenarios are USMCspecific, the challenges of SS can be found in any expeditionary undertakings or operations in austere environments.
\end{abstract}

Keywords: OR in defense, multiple knapsack problem, integer programming, self-sufficiency, Marine Corps 


\section{Introduction}

Self-sufficiency (SS) is the ability to maintain operations without external support or aid. Most organizations can rely on local infrastructure and economy for logistical support in their operations, buying fuel and other supplies locally. For operations in environments with limited infrastructure and limited availability of logistical support, which are common in humanitarian assistance and disaster relief (HADR) (Apte et al. 2015), SS is not merely preferred, but is often necessary for the success of the mission. Similarly, military missions may need to be conducted in regions where there is no logistical support structure. In this paper, we focus on expeditionary missions of the United States Marine Corps (USMC), whose vision statement calls for it to be "focused on executing sustainable expeditionary operations" (USMC, 2009). Though the data and scenarios in this particular application are USMC-specific, the challenges of SS can be found in any expeditionary undertaking or operations in austere environments. The analytical approach and the insights generated are readily generalizable.

Many factors determine SS: resource requirements, size of the operating unit, mission duration, operating environment, and local availability (or unavailability) of resources (Brindel et al. 2013). In the USMC, depending on the mission, SS may be required of an individual warfighter, a battalion, or any unit in between. The ability to share resources is a key factor in SS. The availability of supply locally and the timing of availability of organic (USMC-owned) supply chains (Regnier et al. 2015) determine the degree to which resource demands must be met internally and thus the duration and degree of SS required. SS is also dependent on the operating environment, which affects the requirements for both consumable resources such as water and non-consumable resources such as protective equipment. 
The USMC is called upon to conduct a diverse range of missions in many very different environments. Conducting expeditionary operations - in the absence of sustainment from outside, is one of their defining roles, and the USMC needs to be prepared to send the right size squad with the right equipment in any mission and environment in which they are needed, maintaining capability for the duration of the mission.

The most fundamental SS question is whether the squad in a given scenario can be successful with the items the Marines in the squad are able to carry. That is, SS can be viewed as meeting a desired threshold - the squad, with its selected loads, is either self-sufficient for a given mission or it is not. A second view is that imperfect SS can be measured as a degree or fraction of full SS. However, the duration of the mission also affects SS. A third perspective is that SS is the duration over which the squad can conduct its mission while sustaining itself without external support (Brindel et al. 2013).

SS depends on the squad's load - the items that the squad carries into mission. They need both sustainment items, such as food and water, and mission dependent items, such as combat gear. There may be tradeoffs among items that can substitute for one another. Some items are absolutely required, and other items provide value to the squad but are not strictly necessary. Our model includes each type of item. Each individual Marine has a maximum weight constraint on his or her load. The planning challenge is to select items for the squad's collective load and allocate items among the squad to maximize SS, within the individual weight constraints.

This is both literally and mathematically a knapsack problem; it involves the selection of a set of items to maximize an objective function while satisfying a weight constraint. This application incorporates several different extensions to the traditional knapsack problem. First, it includes multiple knapsacks. The multiple knapsack problem was first developed by Eilon and 
Christofides (1971) as a cargo loading problem, and can be solved using algorithms presented by Martello and Toth (1981) and Pisinger (1999). Second, in addition to the weight constraints, it includes demand constraints, as used by Cappanera (1999), whose model also includes multiple dimensions of item cost; in the Marine squad problem, only weight is used. Algorithms for solving multidimensional knapsack problems with demand constraints are given by Cappanera and Trubian (2005), Arntzen et al. (2006), and Hvattum and Lokketangen (2007). They have been used in capital budgeting by Beaujon et al. (2001), and in location problems by Cappanera (1999) and Plastria (2001). Third, some of the items under consideration can be transferred between Marines, and others (primarily clothing items) cannot. For non-transferable items that are strictly required, e.g. boots, this amounts simply to setting the decision variables for each Marine's boots equal to 1 and decreasing the weight limits by the weight of the boots. There are a few additional unusual properties of the Marine squad knapsack problem; however, each of these can be treated as a relatively trivial modification. This knapsack problem formulation enables us to explore the implications of various definitions of SS and the tradeoffs and associated insights for several USMC training scenarios. For a more detailed review of extensions to the knapsack problem, see Wilbaut et al. (2008).

One unusual aspect of our analysis is that some of the items can be shared among the squad. For instance, in desert terrain, if one Marine carries sunblock, it is very easy for multiple Marines to use that sunblock with no decrease in the benefit that it provides. A rifle or a pair of boots, on the other hand, cannot be shared in this manner. Sustainment items such as water or rations also cannot be shared this way; their benefit applies only to the individual who consumes them. The extent to which the items can be shared helps to determine the demand constraints; 
greater sharing is associated with lower demands. The demand constraints also vary as a function of the duration of the mission.

The resulting optimization problems are NP-hard. However, due to the relatively manageable size of the USMC scenarios, we are still able to obtain numerical solutions for these applications of the model. The goal of our work is to examine under the above-described circumstances what items will be carried by the squad in an optimal solution, and how mission, sustainment requirements, and squad size affect the extent to which a squad can conduct its mission while being self-sufficient. The primary purpose of the analysis is to inform baseline operating procedures and higher-level decision making, and not to apply the optimization model to every individual real-world mission for operational purposes.

\section{Model}

We develop and formulate three different models for the three corresponding interpretations of SS: 1) threshold SS; 2) degree of SS; and 3) duration of SS, using the following notation:

$K \quad$ Number of Marines in the squad; Marines are indexed as $k=1, \ldots, K$

I Number of different types of items the squad may carry, indexed as $i=1, \ldots, I$

$X_{i k}$ Decision variable, the (integer) number of item $i$ carried by Marine $k$

$c_{i} \quad$ Weight in pounds (lbs) of item $i$, each

$w_{k} \quad$ Total weight (lbs) that Marine $k$ can carry ${ }^{1}$

$a_{i} \quad$ Number of Marines who can use one of item $i$

\footnotetext{
${ }^{1}$ This formulation allows different Marines to carry different loads, for example, a given fraction of his or her body weight, though we assume in our numerical analysis that $w_{k}$ is the same for all $k$.
} 
$r_{i} \quad$ Number of Marines who will be required to use item $i$ to carry out the mission

$t_{i} \quad$ An indicator variable specifying whether item $i$ can be transferred among individuals

It should be noted that if item $i$ cannot be shared, then $a_{i}=1$; if all of the Marines can share one of item $i$, then $a_{i}=K$. Typically, either $a_{i}=1$ or $a_{i}=K$, but it is possible that items can be shared by a few Marines. Intermediate levels of $a_{i}$ can also be used to model sharing an item that is feasible but difficult or somewhat degrades its effectiveness in practice. In general, for some items, $r_{i}=K$ for a squad of $K$ Marines, and for some items $r_{i}$ will depend on the duration of the mission. If a consumable item such as food is defined such that one of the item is a day's rations, then $r_{i}=K \times$ the number of days the mission will need to be self-sustaining. The number of Marines in the squad who can use item $i$ is expressed as:

$$
\sum_{k=1}^{K} a_{i} X_{i k}
$$

This term is measured in person-days rather than simply number of people; e.g. if it is 24 for food, then a squad of eight Marines has enough food for three days. The purpose of $t_{i}$ is to ensure that wearable items (typically clothing) are carried and used by the same Marine.

Modeling each Marine's load, rather than the overall squad's load, is important for ensuring that a specified set of items can feasibly be distributed among the squad. When a set of items is split among a group, constraining individual loads is particularly crucial when there are heavy items, or when non-transferable items comprise a large portion of the overall load. In general, however, the overall effectiveness of a solution meeting the constraints will depend only on the combined set of items across the entire squad, not on the individual Marines' loads.

The decision variables are $X_{i k}$ for all $i$ and $k$ : an assignment of a given number of item $i$ to each Marine $k$. The optimal solution will depend on what exactly is meant by SS. We 
consider three different cases as described previously, each of which involves a different set of assumptions. The second case requires assessing the value of each item to the squad, while the third case requires distinguishing explicitly between mission items and sustainment items.

\section{1. Threshold Case}

If SS is viewed as meeting a desired threshold, the question is simply whether the squad can carry out a particular mission without additional support or not. In this case, there is a required set of items that must be carried. Preferences and tradeoffs are irrelevant; it is merely a matter of whether or not it is possible for the squad to carry the required set of items (in an arrangement such that all items can be used as needed). We would like to know whether or not there is an allocation of items $X$ such that:

$$
\begin{aligned}
& \sum_{k=1}^{K} a_{i} X_{i k} \geq r_{i}, i=1, \ldots, I \\
& \sum_{i=1}^{I} c_{i} X_{i k} \leq w_{k}, k=1, \ldots, K, \\
& \left(1-t_{i}\right) X_{i k} \leq 1, \forall i, k \\
& X_{i k} \geq 0, \forall i, k \\
& X_{i k} \text { integer, } \forall i, k
\end{aligned}
$$

That is, we are looking for an allocation of items such that enough Marines are able to use each item, and no Marine is carrying more than the allowable weight limit. If there is an allocation $X$ that satisfies (2), then the squad can be SS. The first constraint ensures that the required quantity of each item is met. The second constraint ensures that every Marine's load is within the allowable weight limit. The third constraint ensures that no Marine is carrying more than one of any non-transferable item. Note that if $t_{i}=0$, i.e. if item $i$ is non-transferable, then $r_{i} \leq K$; no Marine will ever be required to carry more than one of a non-transferable item. This constraint 
could easily be modified to incorporate values of $r_{i}$ greater than $K$ if needed. The fourth and fifth constraints specify that only non-negative integer numbers of items are allowable.

\subsection{Degree Case}

A somewhat broader interpretation of SS is the proportion of the desired items needed for a particular mission that can be carried by the squad. There are several possible ways to model this proportion; we express it as the proportion of overall value that can be achieved by the squad. Note that if the squad is self-sufficient as defined in the threshold case, then this proportion is 1. The Degree case is more useful when no allocation of items satisfying the constraints in the previous case exists. Two additional parameters are required in the Degree case. First, each item is assigned an attribute weight $b_{i}$, representing its relative value to the squad. We use linear value functions for the individual items, where complete value for item $i$ is achieved at $\sum_{k=1}^{K} a_{i} X_{i k}=r_{i}$. Second, the $r_{i}$ parameters are treated as the desired quantities of the items, rather than lower bounds. Therefore, we must introduce a hard lower bound $l_{i}$ (which may be zero) on the items; for instance, if the duration of the mission is three days, the squad must carry enough water to sustain all of the Marines for three days. These lower bounds are included to ensure that the mission can still be conducted. The proportion of overall value is given by the results of the following optimization: 


$$
\begin{array}{ll}
\max _{X} & \sum_{i=1}^{I} b_{i} \frac{\sum_{k=1}^{K} a_{i} X_{i k}}{r_{i}} \\
\text { s.t. } & \sum_{i=1}^{I} c_{i} X_{i k} \leq w_{k}, k=1, \ldots, K, \\
& \sum_{k=1}^{K} X_{i k} \leq\left\lceil\frac{r_{i}}{a_{i}}\right\rceil, i=1, \ldots, I, \\
& \sum_{k=1}^{K} a_{i} X_{i k} \geq l_{i}, i=1, \ldots, I, \\
& \left(1-t_{i}\right) X_{i k} \leq 1, \forall i, k \\
& X_{i k} \geq 0, \forall i, k \\
& X_{i k} \text { integer, } \forall i, k
\end{array}
$$

The objective function is the proportion of the total desired value achieved, where $b_{i}$ reflects the relative importance that the Marines place on each item as described previously. The first constraint is the individual weight constraint as used in (2). The second constraint ensures that the squad will never carry more of a particular type of item than needed. The third constraint sets the lower bounds. The remaining three constraints are identical to those in (2).

\subsection{Duration Case}

This case allows the duration of the mission to vary. In this case, we divide the items explicitly into two types: mission items and sustainment items. Let $I_{m}$ represent the number of mission items, and $I_{s}$ represent the number of sustainment items; $I_{m}+I_{s}=I$. We treat $r_{m}$, i.e. the requirements on mission items, as hard constraints, and maximize the achievable duration given those constraints. This case is useful for missions that require relatively few heavy mission items but are labor intensive, such as humanitarian assistance and disaster relief operations. The optimization problem is: 


$$
\begin{array}{ll}
\max _{X} & \min _{s}\left(\sum_{k=1}^{K} a_{s} X_{s k}\right) \\
\text { s.t. } & \sum_{i=1}^{I} c_{i} X_{i k} \leq w_{k}, k=1, \ldots, K, \\
& \sum_{k=1}^{K} a_{m} X_{m k} \geq r_{m}, m=1, \ldots, I_{m} \\
& \left(1-t_{i}\right) X_{i k} \leq 1, \forall i, k \\
& X_{i k} \geq 0, \forall i, k \\
& X_{i k} \text { integer, } \forall i, k .
\end{array}
$$

The objective function being maximized is the duration over which the amounts of all sustainment items are sufficient to support the squad. As previously, the first constraint is the weight limit on the individual Marines' loads. The second constraint ensures that the squad is carrying a sufficient number of all of the mission items. The last three constraints are the same as in (2) and (3).

\section{Instantiating the Model}

\subsection{Scenarios}

To obtain insights into the impact of several factors on SS, we develop a variety of scenarios on which to apply the model. We focus on the Degree case and the Duration case. The Threshold case is omitted, because the output that it generates is relatively limited compared to the other two cases. The set of factors used to define a scenario is based on our discussions with subject matter experts, and differs somewhat between the Degree and Duration cases. In the Degree case, we consider changes in the environment of the mission, the organizational level of the unit deployed for that mission (number of Marines in the squad), and the duration of the mission. In the Duration case, we consider changes in the environment of the mission and the weight capacity of each Marine. 
The environment of the mission determines the set of items available. We use items based on the Standard Operating Procedures (SOP) policy for Hot and Cold climate training for hiking 20 kilometers; the item lists are given in Appendix A and B, along with all of their associated parameters. Each mission typically requires additional items specific to the tasks the squad of Marines must perform; for example, a combat mission will require combat gear. We incorporated various expeditionary operations that may be relevant to the Marines. The set of scenarios is intended to capture a variety of missions on which to conduct analysis. In the Duration case, it will also be important to distinguish between sustainment items, such as food and water, and mission dependent items; the mission dependent items are treated as constraints, whereas the sustainment items determine the level of duration achieved, as shown in (4).

The characteristics of the scenario will determine the parameter levels to be used in (3) and (4), allowing the objective function and constraints to be specified. For example, in the Degree case, if the scenario is (Hot SOP, 8 Marines, 2 Days), the lower bound on covered canteens of water will be $8 * 2 * l_{\text {canteen }}=8 * 2 * 2=32$. The resulting constraint is: $n_{\text {canteen }} \geq 32$, and since canteens cannot be shared (i.e. $a_{\text {canteen }}=1$ ), the squad must carry at least 32 covered canteens of water.

\subsection{Assessing Value of Individual Items}

Another challenge is specifying the relative value that each type of item provides to the squad, which is an important parameter in the Degree model. We estimated this preference information by assessing the preferences of many individual Marines. To determine the importance of each specific item, we used a numerical scale from 0-10 as a measure of a Marine's assessment of the relative benefit of having the item. We elicited this information from Marines directly. They 
were given a master list of items from the Marine Corps Infantry Training and Readiness Manual (USMC 2013) and requested to assess each item based on either Hot or Cold SOP. These numbers are rescaled and treated as attribute weights in our analysis, as is typically done in multi-attribute value/utility theory (Keeney and Raiffa 1976, Kirkwood 1997); the results of this process are included in the lists in Appendix A and B.

\section{Results}

We implemented the models described in Section 2 across several scenarios, using data obtained from subject matter experts. In the Degree case, the numerical responses capturing the relative preferences of Marines between the possible items were used as the measures of item importance. In the Duration case, the weight constraint on each Marine was allowed to vary from 50 pounds to 150 pounds.

The optimization models were implemented using the general algebraic modeling language (GAMS) (Brooke et al. 1998) using CPLEX as the solver engine. The solutions and their interpretations follow.

\subsection{Results from Degree of SS Case}

We applied the model in the Degree case to 18 different scenarios. The factors that differed between scenarios were the set of available items (Hot SOP, Cold SOP), the size of the squad (4, $8,12)$, and the duration of the mission in days $(2,3,4)$. In each SOP, a desired set of mission items was provided, such that carrying all of the desired mission items was not feasible. The objective of the optimization was to maximize the proportion of overall value that could be achieved for a given scenario. As mentioned previously, the overall values depend on the 
preference information provided by the subject matter experts. For the purposes of this part of our analysis, we assumed that the weight constraint for each Marine was 95 pounds. Table 1 summarizes the results from the Degree of SS model for Hot SOP and Cold SOP with varying squad sizes and durations.

\begin{tabular}{|c|c|c|}
\hline Degree of SS Model & Hot SOP & Cold SOP \\
\hline Squad Size $=4$ & & \\
\hline Duration & Degree of Self-Sufficiency & Degree of Self-Sufficiency \\
\hline 2 & 0.936 & 0.943 \\
\hline 3 & 0.879 & 0.882 \\
\hline 4 & 0.781 & 0.784 \\
\hline Squad Size $=8$ & & \\
\hline Duration & & \\
\hline 2 & 0.951 & 0.950 \\
\hline 3 & 0.903 & 0.910 \\
\hline 4 & 0.809 & 0.817 \\
\hline 3 & & \\
\hline 4 & & \\
\hline Squad Size $=12$ & & \\
\hline Duration & & \\
\hline 2 & & \\
\hline & & \\
\hline & & \\
\hline
\end{tabular}

Table 1: Degree of self-sufficiency attainable for various durations and squad sizes. Note that results should not be compared directly between Hot SOP and Cold SOP, as the baseline set of desired items differs between the two. 
It is interesting to note that the degree of SS consistently increases within the duration as squad size increases for both Hot and Cold SOP, as shown in Table 1. This is due to increased flexibility in how the items can be distributed between individual Marines. However, SS decreases steadily as duration increases. This is due to Marines having to devote more of their weight capacities to sustainment items as the length of the mission increases, which makes it more difficult for them to carry a large proportion of the desired mission items.

It is also interesting to examine which items tended to be left out of the optimal set as duration increased. The entrenching tool, sleeping bag, main pack liner, set of utilities, polypropylene top/bottom (Cold SOP only), and binoculars were frequently included in optimal sets of items for short duration missions, but rarely if ever included for longer duration missions. These results are for the particular scenarios used in the optimizations; one could easily imagine specific missions for which one or more of these items could be crucial.

This conclusion is based on our results, which are to some extent dependent on the values placed on the items by the subject matter experts. When the results were shared with experts, they expressed a common theme that a Marine will only carry items deemed to be essential (from an individual perspective), especially for longer duration missions. Carrying extra items for shorter duration missions, however, is relatively common. This is consistent with some of the optimization results. However, the optimization model is able to incorporate weights, values, requirements, sharing, and transferring more rigorously than could be done with a manual process. To illustrate the benefit over a more informal approach, we apply a heuristic described by the experts: each Marine selects his/her items independently (with no consideration of sharing or transferring) by first choosing the strictly required items to meet the lower bounds, and then adding items in order of value added per unit of weight, while never exceeding $r_{i} / K$ for any 
item $i$. We modify the heuristic slightly to allow omission of the breaching kit despite its lower bound being 1 for the squad, as it weighs 25 pounds, and even the most rudimentary coordination would avoid assigning one to each Marine. The resulting degrees of SS are shown in Table 2. The results are identical regardless of squad size, because for every item $i$, the heuristic leads to each Marine either selecting $r_{i} / K$ of it, or omitting it entirely. Thus, they do not gain any of the sharing and transferring benefits associated with larger squad sizes.

\begin{tabular}{|c|c|c|}
\hline Degree of SS Model & Hot SOP & Cold SOP \\
\hline Heuristic Results & & \\
\hline Duration & Degree of Self-Sufficiency & Degree of Self-Sufficiency \\
\hline 2 & $0.848(0.936)$ & $0.853(0.943)$ \\
\hline 3 & $0.748(0.879)$ & $0.769(0.882)$ \\
\hline 4 & infeasible $(0.781)$ & infeasible $(0.784)$ \\
\hline
\end{tabular}

Table 2: Degree of self-sufficiency attained using a heuristic approach. The optimization model's results for a squad size of 4 are shown in parentheses. Note that because the heuristic does not involve any coordination between the Marines, the results do not differ by squad size.

It is informative to examine the differences between the sets of items selected by the optimization model and the heuristic. For example, in the scenario: (Hot SOP, $K=4$, Duration=3), taking advantage of sharing and transferring allows the optimization model to select entrenching tools and additional MREs, which are not selected using the heuristic. In general, the heuristic suffers from duplication of some of the necessary and/or high-value items across Marines, preventing it from choosing items that are less valuable but still desired. The complete list of items selected by both approaches in this scenario can be found in Appendix C. 


\subsection{Results from Duration of SS Case}

We applied the model in the Duration case to hypothetical scenarios using a squad size of ten.

We considered scenarios based on Hot SOP and Cold SOP, with the required sets of mission items based on input from subject matter experts. We also allowed the individual Marine weight capacities to range from 50 pounds to 150 pounds, in increments of ten. In both Hot and Cold SOP, the problems were infeasible with a weight capacity of 50 pounds, suggesting that the Marines for the given scenarios cannot conduct the mission at all, since they did not even have the capacity to carry only the required mission items. Table 3 shows the numerical results.

\begin{tabular}{|c|c|c|}
\hline Duration of SS Model & & \\
\hline Weight Capacity & Duration: Hot SOP (days) & Duration: Cold SOP (days) \\
\hline 50 & inf & 0.05 \\
\hline 60 & 0.2 & 0.65 \\
\hline 70 & 0.85 & 1.25 \\
\hline 80 & 1.4 & 1.8 \\
\hline 90 & 2.1 & 2.4 \\
\hline 100 & 2.6 & 3 \\
\hline 110 & 3.2 & 3.6 \\
\hline 120 & 3.9 & 4.3 \\
\hline 130 & 4.3 & 4.7 \\
\hline 140 & 5.2 & 5.6 \\
\hline 150 & 5.7 & inf \\
\hline
\end{tabular}

Table 3: Duration of self-sufficiency attainable by weight capacity. In both environments, the problems were infeasible with a weight capacity of 50 pounds, i.e. the Marines did not have the capacity to carry the required mission items. 
As one would expect, once the mission becomes feasible, the achievable duration increases as the weight constraint increases. The increase in duration is close to linear in the weight constraint for both Hot and Cold $\mathrm{SOP}^{2}$. Thus, we can state that in these two environments, increasing the duration by 12 hours (half a day) involves increasing the weight limit by approximately $8-10$ pounds.

We also wanted to gain insight into understanding what items are carried by a squad of Marines under certain scenarios. As an example, Appendix D lists the items and total number carried by the squad in the Hot SOP environment and a 100 pound weight constraint with an optimal duration of 2.6 days. As the weight limit increases, more and more sustainment items are carried in the optimal solution, and transferable mission items are sometimes reallocated when a more efficient distribution becomes possible.

\section{Conclusion}

We explored different factors impacting the self-sufficiency of a squad of Marines. Our study suggested that the principal influences are the squad size, the time for which the squad must be self-sufficient, the type and environment of the mission, and the weight constraint. The most critical factor was the duration of time for which self-sufficiency was desired. For this reason, we developed optimization models to study self-sufficiency in terms of duration while sharing certain items within a squad.

We formulated models for analyzing the self-sufficiency of the squad according to three different interpretations of self-sufficiency that are relevant in the context of this work. The

\footnotetext{
${ }^{2}$ It is not precisely linear, because the optimization model considers integer numbers of items, and thus is expected to have "jumps" in the objective function value.
} 
Threshold case is useful for determining whether or not the squad is self-sufficient for a specific mission with a fixed duration. The Degree case examines how self-sufficient the squad can be given a fixed duration and a desired set of items. The output of this model is a number between 0 and 1, with 1 being fully self-sufficient; the number represents the proportion of the overall desired value that the squad is able to achieve. The Duration case maximizes the time for which the squad can be self-sufficient while still carrying all the needed mission items, within the weight capacity of each Marine. The Degree and Duration cases were implemented for several scenarios using sets of items derived from the SOP policy for Hot and Cold climate training of the Infantry Training Battalion of the School of Infantry-East.

The analysis of the results in the computational experiment for the Degree case indicates that self-sufficiency consistently increases within a given duration as squad size increases for each scenario. This result can be explained by observing that as the squad size increases, the flexibility for sharing the items also increases. On the other hand, self-sufficiency decreases as duration increases, because more sustainment items have to be carried when longer durations of self-sufficiency are needed. The results of the optimizations provide a sense of the degradation of mission effectiveness that can be expected when duration increases. They also illustrate a clear benefit over the use of an informal heuristic to select items.

The results from the Duration case confirm that as the weight capacity increases, the duration for being SS increases. The results provide some insight regarding the quantitative relationship between weight capacity and duration; in the scenarios considered, an increase of the weight constraint by approximately 8-10 pounds corresponds to a half-day increase in duration.

There are a few ways in which this analysis could be expanded in the future. First, some items, such as portable photovoltaic arrays and rechargeable batteries, or water purifiers, can 
reduce the requirements for other items, such as batteries and drinking water. Including total or partial substitution in the model could yield additional insights. Second, the primary current limitation is the availability of data; this study considers only the data provided to the authors by the USMC. The models used in the paper are flexible, and could certainly be applied to additional scenarios, as well as incorporate different preference information. Finally, as stated previously, the approach and similar optimization models could be applied to other types of expeditionary ventures that involve a team sharing equipment or supplies, such as mountaineering expeditions, geographical mapping of unknown territories, or working on oil rigs at remote locations on open waters. One particular application is analyzed in this paper, but the underlying methods are not specific to the USMC nor to military operations.

\section{Acknowledgments}

We are grateful to the Office of Naval Research (ONR) for their support of this work. The views expressed in the paper are our own, and do not necessarily reflect those of ONR, the USMC, or the United States Department of Defense.

\section{References}

Apte, A., Khawam, J., Regnier, E., \& Simon, J. (2015). Complexity and Self-Sustainment in Disaster Response Supply Chains. Decision Sciences. Forthcoming.

Arntzen, H., Hvattum, L. M., \& Lokketangen, A. (2006). Adaptive memory search for multidemand multidimensional knapsack problems. Computers \& Operations Research 33 2508-2525.

Beaujon, G. J., Marin, S. P., \& McDonald, G. C. (2001). Balancing and optimizing a portfolio of R\&D projects. Naval Research Logistics 48 18-40.

Brindel, J. A., Fowler, D.A. \& Meche, C.J. (2013). "Defining Self-Sufficiency in the United States Marine Corps", MBA Professional Report, Naval Postgraduate School, Monterey, CA. 
Brooke, A., D. Kendrick, A. Meeraus, R. Raman. (1998). 'GAMS, a User's Guide.' GAMS Development Corporation. Online, retrieved 11/2/2014, www.gams.com

Cappanera, P. (1999). Discrete facility location and routing of obnoxious facilities. Ph.D. Thesis. University of Milano, Milano, Italy.

Cappanera, P., \& Trubian, M. (2005). A local search based heuristic for the demand constrained multidimensional knapsack problem. INFORMS Journal on Computing 17 82-98.

Eilon, S., \& Christofides, N. (1971). The loading problem. Management Science 17 259-268.

Hvattum, L. M., \& Lokketangen, A. (2007). Experiments using scatter search for the multidemand multidimensional knapsack problem. In Metaheuristics: Progress in Complex Systems Optimization (K. F. Doerner, M. Gendreau, P. Greistorfer, W. Gutjahr, R.F. Hartl, \& M. Reimann, eds.) pp. 3-24. New York: Springer.

Keeney, R. L., \& Raiffa, H. (1976). Decisions with Multiple Objectives: Preferences and Value Tradeoffs. John Wiley \& Sons, New York.

Kirkwood, C. W. (1997). Strategic Decision Making: Multiobjective Decision Analysis with Spreadsheets. Duxbury Press, Belmont, CA.

Martello, S., \& Toth, P. (1981). A bound and bound algorithm for the zero-one multiple knapsack problem. Discrete Applied Mathematics 3(4) 275-288.

Pisinger, D. (1999). An exact algorithm for large multiple knapsack problems. European Journal of Operational Research 114 528-541.

Plastria, F. (2001). Static competitive facility location: an overview of optimization approaches. European Journal of Operational Research 129 461-470.

Regnier, E., Simon, J., Nussbaum, D., \& Whitney, L. (2015). The Fuel Multiplier in Multi-Stage Supply Chains. Journal of Defense Modeling and Simulation 12(1) 5-17.

USMC (2009). United States Marine Corps Expeditionary Energy Strategy and Implementation Plan - Bases-to-Battlefield.

http://www.hqmc.marines.mil/Portals/160/Docs/USMC\%20Expeditionary\%20Energy\%20 Strategy\%20\%20Implementation\%20Planning\%20Guidance.pdf. Retrieved May 4, 2015.

USMC (2013). Infantry Training and Readiness Manual. NAVMC 3500.44B. http://www.marines.mil/Portals/59/NAVMC 3500.44B.pdf. Retrieved June 21, 2016.

Wilbaut, C., Hanafi, S., \& Salhi, S. (2008). A survey of effective heuristics and their application to a variety of knapsack problems. IMA Journal of Management Mathematics 19227 244. 


\section{APPENDIX A: Items included in the Hot SOP scenarios}

\begin{tabular}{|c|c|c|c|c|c|c|c|}
\hline & $\begin{array}{c}\text { Weight } \\
\text { (lbs.) } \\
\left(c_{i}\right)\end{array}$ & $\begin{array}{c}\text { Value } \\
\left(b_{i}\right)\end{array}$ & 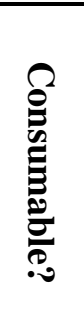 & 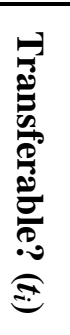 & $\begin{array}{c}\text { Lower } \\
\text { bound }\left(l_{i}\right) \\
\text { per Marine } \\
\text { (per day if } \\
\text { consumable, } \\
\text { Degree case } \\
\text { only) }\end{array}$ & $\begin{array}{l}\text { Requirement } \\
\left(r_{i}\right) \text { per Marine } \\
\text { (per day, if } \\
\text { consumable) }\end{array}$ & $\begin{array}{c}\text { Number } \\
\text { of } \\
\text { Marines } \\
\text { who can } \\
\text { share one } \\
\text { item }\left(a_{i}\right)\end{array}$ \\
\hline 2 Grenade pouches & 0.33 & 7.1 & No & 1 & 0 & 2 & 1 \\
\hline $\begin{array}{l}3 \text { Magazine } \\
\text { pouches }\end{array}$ & 0.33 & 7.1 & No & 1 & 0 & 6 & 1 \\
\hline $\begin{array}{l}\text { BAT and HIIDE } \\
\text { System (Biometrics } \\
\text { and Handheld } \\
\text { Interagency } \\
\text { Detection System) } \\
\text { Census Operations }\end{array}$ & 2.2 & 9 & No & 1 & 1 & 1 & 13 \\
\hline Batteries PRC-152 & 0.7 & 8.3 & Yes & 1 & 4 & 6 & 13 \\
\hline $\begin{array}{l}\text { Binoculars/Spotting } \\
\text { scope }\end{array}$ & 3.94 & 4.7 & No & 1 & 0 & 1 & 4 \\
\hline Boonie cover & 0.15 & 8.3 & No & 0 & 1 & 1 & 1 \\
\hline Boots & 3.12 & 5 & No & 0 & 1 & 1 & 1 \\
\hline $\begin{array}{l}\text { Breaching kit (used } \\
\text { for raids) }\end{array}$ & 25 & 9 & No & 1 & 1 & 1 & 13 \\
\hline $\begin{array}{l}\text { Camel back } \\
\text { (hydration) }\end{array}$ & 6.91 & 9.5 & Yes & 1 & 1 & 1 & 1 \\
\hline Cammie paint & 0.14 & 2.9 & Yes & 1 & 0 & 1 & 4 \\
\hline Canteen cup & 0.18 & 4 & No & 1 & 0 & 1 & 1 \\
\hline Combat tarp & 2.3 & 6.4 & No & 0 & 0 & 1 & 1 \\
\hline $\begin{array}{l}\text { Covered canteens } \\
\text { with one quart } \\
\text { water each }\end{array}$ & 2.3 & 9.5 & Yes & 1 & 2 & 2 & 1 \\
\hline Dog tags & 0.1 & 4.5 & No & 1 & 1 & 1 & 1 \\
\hline Dump pouch & 0.33 & 7.1 & No & 1 & 1 & 1 & 1 \\
\hline $\begin{array}{l}\text { E-tool with carrier } \\
\text { (entrenching tool } \\
\text { with case) }\end{array}$ & 2.7 & 6 & No & 1 & 0 & 1 & 1 \\
\hline
\end{tabular}




\begin{tabular}{|c|c|c|c|c|c|c|c|}
\hline $\begin{array}{l}\text { Eye protection/ear } \\
\text { protection }\end{array}$ & 0.31 & 7.2 & No & 1 & 0 & 1 & 1 \\
\hline First aid kit & 4 & 8.3 & No & 1 & 1 & 2 & 1 \\
\hline Gloves & 0.32 & 4.7 & No & 0 & 1 & 1 & 1 \\
\hline Gortex top/bottom & 2.97 & 4.1 & No & 0 & 0 & 0 & 1 \\
\hline Helmet with cover & 3.5 & 9.3 & $\mathrm{No}$ & 0 & 1 & 1 & 1 \\
\hline $\begin{array}{l}\text { Hip belt (uniform } \\
\text { utility) }\end{array}$ & 0.3 & 2.7 & No & 0 & 1 & 1 & 1 \\
\hline Hygiene gear & 2 & 5.8 & Yes & 0 & 0 & 0 & 1 \\
\hline ID card & 0.03 & 2.2 & No & 1 & 1 & 1 & 1 \\
\hline $\begin{array}{l}\text { Individual water } \\
\text { purifier (if fresh } \\
\text { water sources } \\
\text { available) } \\
\end{array}$ & 0.88 & 9 & No & 1 & 1 & 1 & 1 \\
\hline $\begin{array}{l}\text { LBV (load bearing } \\
\text { vest) }\end{array}$ & 1.8 & 7 & No & 0 & 0 & 1 & 1 \\
\hline $\begin{array}{l}\text { Main pack liner } \\
\text { (main pack bag) }\end{array}$ & 9 & 6.7 & No & 0 & 0 & 1 & 1 \\
\hline Map pens & 0.02 & 8.3 & No & 1 & 0 & 1 & 1 \\
\hline $\begin{array}{l}\text { Metal Detector } \\
\text { (IED environment) }\end{array}$ & 6.11 & 9 & No & 1 & 1 & 1 & 13 \\
\hline MREs & 3.9 & 9.7 & Yes & 1 & 1 & 2 & 1 \\
\hline Note taking gear & 0 & 8.3 & No & 1 & 0 & 1 & 1 \\
\hline $\begin{array}{l}\text { NVG PVS } 14 \\
\text { (Night vision) }\end{array}$ & 0.86 & 4.7 & No & 1 & 1 & 1 & 1 \\
\hline Poncho liner & 1.6 & 6.3 & $\mathrm{No}$ & 0 & 0 & 1 & 1 \\
\hline Protractor & 0 & 8.3 & No & 1 & 0 & 1 & 1 \\
\hline $\begin{array}{l}\text { Pyro set } \\
\text { (smoke/flares IAW } \\
\text { signal plan) }\end{array}$ & 1.3 & 8 & Yes & 1 & 1 & 2 & 4 \\
\hline $\begin{array}{l}\text { Radio PRC-152 } \\
\text { encrypted }\end{array}$ & 2 & 8.3 & No & 1 & 0 & 1 & 13 \\
\hline Rifle with sling & 8.35 & 8.9 & No & 1 & 0 & 1 & 1 \\
\hline
\end{tabular}




\begin{tabular}{|l|r|r|r|r|r|r|r|}
$\begin{array}{l}\text { Sapi plate carrier } \\
\text { with Sapis }\end{array}$ & 19 & 9.1 & No & 0 & 0 & 1 & 1 \\
\hline $\begin{array}{l}\text { Set of utilities } \\
\text { (Marine Corps } \\
\text { combat utility, } \\
\text { blouse, and trouser) }\end{array}$ & 2.97 & 4.1 & No & 0 & 0 & 1 & 1 \\
\hline $\begin{array}{l}\text { Skivvy shirt (T- } \\
\text { shirt) }\end{array}$ & 0.18 & 4.9 & No & 0 & 1 & 1 & 1 \\
\hline SL3 complete & 0 & 8.3 & No & 1 & 0 & 1 & 1 \\
\hline $\begin{array}{l}\text { Sleeping bag, bivvy } \\
\text { cover, and mat }\end{array}$ & 7.4 & 6.2 & No & 1 & 0 & 1 & 1 \\
\hline $\begin{array}{l}\text { Socks } \\
\text { Sun Block }\end{array}$ & 0.16 & 7.7 & No & 0 & 1 & 1 \\
\hline Underwear & 0.25 & 5 & No & 0 & 1 & & 1 \\
\hline
\end{tabular}




\section{APPENDIX B: Items included in the Cold SOP scenarios}

\begin{tabular}{|c|c|c|c|c|c|c|c|}
\hline & $\begin{array}{c}\text { Weight } \\
\text { (lbs.) } \\
\left(c_{i}\right)\end{array}$ & $\begin{array}{c}\text { Value } \\
\left(b_{i}\right)\end{array}$ & 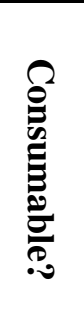 & 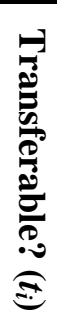 & $\begin{array}{c}\text { Lower } \\
\text { bound }\left(l_{i}\right) \\
\text { per Marine } \\
\text { (per day if } \\
\text { consumable } \\
\text {, Degree } \\
\text { case only) }\end{array}$ & $\begin{array}{l}\text { Requirement } \\
\left(r_{i}\right) \text { per Marine } \\
\text { (per day, if } \\
\text { consumable) }\end{array}$ & $\begin{array}{l}\text { Number of } \\
\text { Marines } \\
\text { who can } \\
\text { share one } \\
\text { item }\left(a_{i}\right)\end{array}$ \\
\hline 2 Grenade pouches & 0.33 & 7.1 & No & 1 & 0 & 2 & 1 \\
\hline $\begin{array}{l}3 \text { Magazine } \\
\text { pouches }\end{array}$ & 0.33 & 7.1 & No & 1 & 0 & 6 & 1 \\
\hline $\begin{array}{l}\text { BAT and HIIDE } \\
\text { System (Biometrics } \\
\text { and Handheld } \\
\text { Interagency } \\
\text { Detection System) } \\
\text { Census Operations }\end{array}$ & 2.2 & 9 & No & 1 & 1 & 1 & 13 \\
\hline Batteries PRC-152 & 0.7 & 8.3 & Yes & 1 & 4 & 6 & 13 \\
\hline $\begin{array}{l}\text { Binoculars/Spottin } \\
\text { g scope }\end{array}$ & 3.94 & 4.7 & No & 1 & 0 & 1 & 4 \\
\hline Boonie cover & 0.15 & 8.3 & $\mathrm{No}$ & 0 & 1 & 1 & 1 \\
\hline Boots & 3.12 & 5 & No & 0 & 1 & 1 & 1 \\
\hline $\begin{array}{l}\text { Breaching kit (used } \\
\text { for raids) }\end{array}$ & 25 & 9 & No & 1 & 1 & 1 & 13 \\
\hline $\begin{array}{l}\text { Camel back } \\
\text { (hydration) }\end{array}$ & 6.91 & 9.5 & Yes & 1 & 1 & 1 & 1 \\
\hline Cammie paint & 0.14 & 2.9 & Yes & 1 & 0 & 1 & 4 \\
\hline Canteen cup & 0.18 & 4 & No & 1 & 0 & 1 & 1 \\
\hline Combat tarp & 2.3 & 6.4 & $\mathrm{No}$ & 0 & 0 & 1 & 1 \\
\hline $\begin{array}{l}\text { Covered canteens } \\
\text { with one quart } \\
\text { water each }\end{array}$ & 2.3 & 9.5 & Yes & 1 & 2 & 2 & 1 \\
\hline Dog tags & 0.1 & 4.5 & No & 1 & 1 & 1 & 1 \\
\hline Dump pouch & 0.33 & 7.1 & No & 1 & 1 & 1 & 1 \\
\hline $\begin{array}{l}\text { E-tool with carrier } \\
\text { (entrenching tool } \\
\text { with case) }\end{array}$ & 2.7 & 6 & No & 1 & 0 & 1 & 1 \\
\hline $\begin{array}{l}\text { Eye protection/ear } \\
\text { protection }\end{array}$ & 0.31 & 7.2 & No & 1 & 0 & 1 & 1 \\
\hline
\end{tabular}




\begin{tabular}{|c|c|c|c|c|c|c|c|}
\hline First aid kit & 4 & 8.3 & No & 1 & 1 & 2 & 1 \\
\hline $\begin{array}{l}\text { Glove inserts (cold } \\
\text { weather gloves and } \\
\text { mittens) }\end{array}$ & 1.33 & 0.4 & No & 0 & 0 & 1 & 1 \\
\hline Glove shells & 0.3 & 4.3 & No & 0 & 1 & 1 & \\
\hline Gloves & 0.32 & 4.7 & No & 0 & 1 & 1 & 1 \\
\hline Gortex top/bottom & 2.97 & 4.1 & No & 0 & 0 & 0 & 1 \\
\hline Helmet with cover & 3.5 & 9.3 & No & 0 & 1 & 1 & 1 \\
\hline $\begin{array}{l}\text { Hip belt (uniform } \\
\text { utility) }\end{array}$ & 0.3 & 2.7 & No & 0 & 1 & 1 & 1 \\
\hline Hygiene gear & 2 & 5.8 & Yes & 0 & 0 & 0 & 1 \\
\hline ID card & 0.03 & 2.2 & No & 1 & 1 & 1 & 1 \\
\hline $\begin{array}{l}\text { Individual water } \\
\text { purifier (if fresh } \\
\text { water sources } \\
\text { available) } \\
\end{array}$ & 0.88 & 9 & No & 1 & 1 & 1 & 1 \\
\hline $\begin{array}{l}\text { Main pack liner } \\
\text { (main pack bag) }\end{array}$ & 9 & 6.7 & No & 0 & 0 & 1 & 1 \\
\hline Map pens & 0.02 & 8.3 & No & 1 & 0 & 1 & 1 \\
\hline $\begin{array}{l}\text { Metal detector } \\
\text { (IED environment) }\end{array}$ & 6.11 & 9 & No & 1 & 1 & 1 & 13 \\
\hline MREs & 3.9 & 9.7 & Yes & 1 & 1 & 2 & 1 \\
\hline $\begin{array}{l}\text { Neck gaiter (cap, } \\
\text { coyote, micro } \\
\text { fleece) }\end{array}$ & 0.12 & 7.4 & No & 0 & 0 & 1 & 1 \\
\hline Note taking gear & 0 & 8.3 & No & 1 & 0 & 1 & 1 \\
\hline $\begin{array}{l}\text { NVG PVS } 14 \\
\text { (Night vision) }\end{array}$ & 0.86 & 4.7 & No & 1 & 1 & 1 & 1 \\
\hline $\begin{array}{l}\text { Poly Pro } \\
\text { top/bottom } \\
\text { (undershirt, } \\
\text { drawers, cold } \\
\text { weather, flame } \\
\text { resistant) }\end{array}$ & 2 & 0.6 & No & 0 & 0 & 1 & 1 \\
\hline Poncho liner & 1.6 & 6.3 & No & 0 & 0 & 1 & 1 \\
\hline Protractor & 0 & 8.3 & No & 1 & 0 & 1 & 1 \\
\hline Pullover fleece & 0.7 & 6.5 & No & 0 & 0 & 1 & 1 \\
\hline
\end{tabular}




\begin{tabular}{|c|c|c|c|c|c|c|c|}
\hline $\begin{array}{l}\text { Pyro set } \\
\text { (smoke/flares IAW } \\
\text { signal plan) }\end{array}$ & 1.3 & 8 & Yes & 1 & 1 & 2 & 4 \\
\hline $\begin{array}{l}\text { Radio PRC-152 } \\
\text { encrypted }\end{array}$ & 2 & 8.3 & No & 1 & 0 & 1 & 13 \\
\hline Rifle with sling & 8.35 & 8.9 & No & 1 & 0 & 1 & 1 \\
\hline $\begin{array}{l}\text { Sapi plate carrier } \\
\text { with Sapis }\end{array}$ & 19 & 9.1 & No & 0 & 0 & 1 & 1 \\
\hline $\begin{array}{l}\text { Set of utilities } \\
\text { (Marine Corps } \\
\text { combat utility, } \\
\text { blouse and trouser) }\end{array}$ & 2.97 & 4.1 & No & 0 & 0 & 1 & 1 \\
\hline $\begin{array}{l}\text { Skivvy shirt (T- } \\
\text { shirt) }\end{array}$ & 0.18 & 4.9 & No & 0 & 1 & 1 & 1 \\
\hline SL3 complete & 0 & 8.3 & No & 1 & 0 & 1 & 1 \\
\hline $\begin{array}{l}\text { Sleeping bag, bivvy } \\
\text { cover and mat }\end{array}$ & 7.4 & 6.2 & No & 1 & 0 & 1 & 1 \\
\hline Socks & 0.16 & 7.7 & No & 0 & 1 & 1 & 1 \\
\hline Underwear & 0.25 & 5 & No & 0 & 0 & 1 & 1 \\
\hline
\end{tabular}




\section{Appendix C: Total number of items carried by the squad: Degree case, Hot SOP, $K=4$, Duration $=3$}

\begin{tabular}{|c|c|c|}
\hline Items & $\begin{array}{l}\text { Total Carried } \\
\text { by the Squad: } \\
\text { Heuristic }\end{array}$ & $\begin{array}{l}\text { Total Carried } \\
\text { by the Squad: } \\
\text { Optimization }\end{array}$ \\
\hline 2 Grenade Pouches & 8 & 8 \\
\hline 3 Magazine pouches & 24 & 24 \\
\hline $\begin{array}{l}\text { BAT and HIIDE System (Biometrics and } \\
\text { Handheld Interagency Detection System) Census } \\
\text { Operations }\end{array}$ & 4 & 1 \\
\hline Batteries PRC-152 & 48 & 6 \\
\hline Boonie cover & 4 & 4 \\
\hline Boots & 4 & 4 \\
\hline Breaching kit (used for raids) & 0 & 1 \\
\hline Camel back (hydration) & 12 & 12 \\
\hline Cammie paint & 12 & 3 \\
\hline Combat tarp & 4 & 4 \\
\hline Covered canteens with one quart water each & 24 & 24 \\
\hline Dog tags & 4 & 4 \\
\hline Dump pouch & 4 & 4 \\
\hline E-tool with carrier (entrenching tool with case) & 0 & 3 \\
\hline Eye protection/ear protection & 4 & 4 \\
\hline First aid kit & 4 & 4 \\
\hline Gloves & 4 & 4 \\
\hline Gortex top/bottom & 0 & 0 \\
\hline Helmet with cover & 4 & 4 \\
\hline Hip belt (uniform utility) & 4 & 4 \\
\hline Hygiene gear & 0 & 0 \\
\hline ID card & 4 & 4 \\
\hline $\begin{array}{l}\text { Individual water purifier (if fresh water sources } \\
\text { available) }\end{array}$ & 4 & 4 \\
\hline LBV (load bearing vest) & 4 & 4 \\
\hline Map pens & 4 & 4 \\
\hline Metal Detector (IED environment) & 4 & 1 \\
\hline MREs & 12 & 24 \\
\hline Note taking gear & 4 & 4 \\
\hline NVG PVS 14 (Night vision) & 4 & 4 \\
\hline Poncho liner & 4 & 2 \\
\hline Protractor & 4 & 4 \\
\hline Pyro set (smoke/flares IAW signal plan) & 16 & 6 \\
\hline Radio PRC-152 encrypted & 4 & 1 \\
\hline Rifle with sling & 0 & 0 \\
\hline Sapi plate carrier with Sapis & 0 & 0 \\
\hline Skivvy shirt (T-shirt) & 4 & 4 \\
\hline SL3 complete & 4 & 4 \\
\hline Socks & 4 & 4 \\
\hline Sun Block & 12 & 1 \\
\hline Underwear & 4 & 4 \\
\hline
\end{tabular}




\section{Appendix D: Total number of items carried by the squad: Duration case, Hot SOP, 100 lb. weight limit}

\begin{tabular}{|c|c|}
\hline Items & Total Carried by the Squad \\
\hline 3 Magazine pouches & 60 \\
\hline $\begin{array}{l}\text { BAT and HIIDE System (Biometrics and } \\
\text { Handheld Interagency Detection System) Census } \\
\text { Operations }\end{array}$ & 1 \\
\hline Batteries PRC-152 & 9 \\
\hline Boonie cover & 10 \\
\hline Boots & 10 \\
\hline Breaching kit (used for raids) & 1 \\
\hline Camel back (hydration) & 26 \\
\hline Cammie paint & 1 \\
\hline Combat tarp & 10 \\
\hline Covered canteens with one quart water each & 54 \\
\hline Dog tags & 10 \\
\hline Dump pouch & 10 \\
\hline E-tool with carrier (entrenching tool with case) & 10 \\
\hline Eye protection/ear protection & 10 \\
\hline First aid kit & 10 \\
\hline Gloves & 10 \\
\hline Gortex top/bottom & 10 \\
\hline Helmet with cover & 10 \\
\hline Hip belt (uniform utility) & 10 \\
\hline Hygiene gear & 1 \\
\hline ID card & 10 \\
\hline $\begin{array}{l}\text { Individual water purifier (if fresh water sources } \\
\text { available) }\end{array}$ & 10 \\
\hline LBV (load bearing vest) & 10 \\
\hline Map pens & 10 \\
\hline Metal Detector (IED environment) & 1 \\
\hline MREs & 26 \\
\hline Note taking gear & 10 \\
\hline NVG PVS 14 (Night vision) & 10 \\
\hline Poncho liner & 10 \\
\hline Protractor & 10 \\
\hline Pyro set (smoke/flares IAW signal plan) & 7 \\
\hline Radio PRC-152 encrypted & 1 \\
\hline Rifle with sling & 10 \\
\hline Sapi plate carrier with Sapis & 10 \\
\hline Skivvy shirt (T-shirt) & 10 \\
\hline SL3 complete & 10 \\
\hline Socks & 10 \\
\hline Sun Block & 3 \\
\hline Underwear & 10 \\
\hline
\end{tabular}

